\title{
The Effect of Carprofen Treatment on Conception Rate After Insemination in Cows with Increased Days in Milk
}

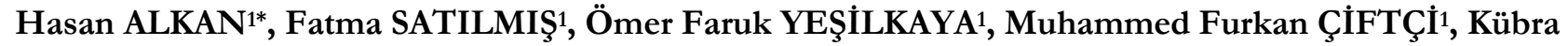 \\ KARAKAŞ ALKAN ${ }^{1}$, Hüseyin ERDEM ${ }^{1}$
}

\author{
${ }^{1}$ Selcuk University, Faculty of Veterinary Medicine, Department of Obstetrics and Gynecology, 42250, Konya, Turkey
}

\section{ABSTRACT}

In this study the effect of carprofen treatment on conception rate after insemination in Holstein cows that did not conceive for a long time after parturition was evaluated. In the study, 200 Holstein cows with days in milk $>120$ were used. A progesterone + ovsynch-based estrus synchronization protocol was applied to the cows included in the study. For this purpose, the progesterone device was placed intravaginally together with GnRH injection. Seven days later, the progesterone source was removed from the vagina and $\mathrm{PGF}_{2 \alpha}$ injection was administered. GnRH injection was administered 48 hours following $\mathrm{PGF}_{2 \alpha}$ injection and fixed-time insemination was performed 12-16 hours later. After insemination, animals were randomly divided into 2 groups. Subcutaneous carprofen was applied to the carprofen group $(n=100)$ on the 14th day after insemination and physiological saline was applied to the control group $(n=100)$ on the same day. Three cows from the carprofen group and 5 cows from the control group were excluded from the study for various reasons. The pregnancy rate was $42.26 \%$ (41/97) in the carprofen group and $25.26 \%(24 / 95)$ in the control group $(\mathrm{p}<0.05)$. However, the rate of conception was found to be the lowest $(10.52 \%)$ in cows with high milk yield $(>30 \mathrm{~kg})$ in the control group. In addition, it was found that carprofen administration to cows with high milk yield increased the rate of conception. However, it was determined that the days in milk had no effect on pregnancy rate. As a result, it was concluded that the administration of carprofen on the 14th day after insemination to cows who could not conceive for a long time after parturition may be effective in increasing the rate of conception.

Keywords: Carprofen, cow, days in milk, milk yield, $\underset{* * *}{\text { pregnancy rate. }}$

\section{Sağımda Geçen Gün Süresi Artmış Olan İneklerde Tohumlama Sonrası Karprofen Uygulamasının Gebe Kalma Oranı Üzerine Etkisi \\ ÖZ}

Bu çalı̧mada doğumdan sonra uzun süre gebeliğin sağlanamadığı Holstein ırkı ineklerde, tohumlama sonrası karprofen uygulamasının gebe kalma oranı üzerine etkisi değerlendirilmiştir. Çalışmada sağımda geçen gün süresi $>120$ gün olan 200 Holstein ırkı inek kullanıldı. Çalışmaya dahil edilen ineklere progesteron+ovsynch esaslı östrüs senkronizasyon protokolü uyguland. Bu amaçla GnRH enjeksiyonu ile birlikte progesteron kaynağı intravaginal olarak yerleştirildi. Yedi gün sonra progesteron kaynağı vaginadan uzaklaştırıldı ve $\mathrm{PGF}_{2 \alpha}$ enjeksiyonu yapıldı. PGF $F_{2 \alpha}$ enjeksiyonundan 48 saat sonra GnRH enjeksiyonu uyguland1 ve 12-16 saat sonra ineklere sabit zamanlı tohumlama yapıldı. Tohumlama sonrası hayvanlar rastgele olarak 2 gruba ayrildı. Karprofen grubuna $(n=100)$ tohumlama sonrası 14. gün deri altı karprofen ve kontrol grubuna $(n=100)$ ise aynı gün fizyolojik tuzlu su uygulandı. Karprofen grubundan 3 ve kontrol grubundan ise 5 inek çeşitli nedenlerle çalışmadan çıkarıldı. Gebe kalma oranı; karprofen grubunda \%42,26 (41/97), kontrol grubunda ise \%25,26 (24/95) olarak belirlendi ( $\mathrm{p}<0,05)$. Bununla birlikte kontrol grubunda yüksek süt verimli $(\geq 30 \mathrm{~kg})$ ineklerde gebe kalma oranları en düşük $(\% 10,52)$ bulundu. Ayrıca yüksek süt verimli ineklere karprofen uygulamasının gebe kalma oranını artırdığı tespit edildi. Ancak sağımda geçen gün süresinin gebelik oranı üzerine etkisinin olmadığı belirlendi. Sonuç olarak doğumdan sonra uzun bir süre gebe kalamamış ineklere, tohumlama sonrası 14. günde karprofen uygulamasının gebe kalma oranını artırmada etkili olabileceği kanısına varildı.

Anahtar Kelimeler: Gebelik oran1, inek, karprofen, sağımda geçen gün süresi, süt verimi.

\footnotetext{
To cite this article: Alkan H. Satılmus F. Yeşilkaya Ö.F. Ciftçi M.F. Karakaş Alkan K. Erdem H. The Effect of Carprofen Treatment on Conception Rate After Insemination in Cows with Increased Days in Milk. Kocatepe Vet J. (2021) 14(1):83-90

Submission: 29.12.2020 Accepted: 11.02.2021 Published Online: 21.02.2021

ORCID ID; HA: 0000-0001-8332-5334, FS: 0000-0002-9877-8405, ÖFY: 0000-0002-7721-2576, MFC: 0000-0001-8333-6500, KKA: 0000-0001-9177-9299, HE: 0000-0002-1416-5354

*Corresponding author e-mail: hasanalkan@selcuk.edu.tr
} 


\section{GİRİ̧̧}

İneklerde yapılan islah çalışmaları ve geliştirilen biyoteknolojik yöntemler sayesinde süt verim düzeylerinde önemli artışlar sağlanmasına rağmen fertilite parametrelerinde aynı başarı elde edilememiştir. En önemli fertilite parametresi her inekten yılda bir kez sağlıklı buzağı elde edilmesidir. Bunun gerçekleşebilmesi için başarnlı bir doğum $(0$. gün), sorunsuz bir postpartum dönem (0-42. gün) ve ilerleyen dönemde (42-90. gün) gebeliğin tekrardan sağlanmas1 gerekmektedir. Ancak çoğu sütçü inek işletmesinde bu şartlar sağlanamadığ1 için doğum-gebe kalma aralığ1 uzamakta ve gebelik başına düşen tohumlama sayısı artmaktadır. Dolayısıyla gebelik başına düşen maliyetin artması veya gebeliğin elde edilememesine bağlı olarak, ineğin damızlık değerinin düşmesi günümüz süt sığırı işletmelerinin en önemli ekonomik sorunu haline gelmiştir (Bartlett ve ark. 1986, Dochi ve ark. 2008, Perez-Marin ve ark. 2012). Embriyonik ölümlerin sütçü ineklerin doğumdan sonra istenilen aralıklarda gebe kalamamasında önemli bir sebep olduğu bildirilmektedir (Santos ve ark. 2004, Diskin ve ark. 2016). Yapilan çalışmalarda bu ölümlerin büyük bir kısmının ilk birkaç hafta içerisinde meydana geldiği tespit edilmiştir. Özellikle gebelik kayıplarının \%70-80'i gebeliğin 8-16. günleri arasında meydana gelmektedir (Thatcher ve ark. 1994, Santos ve ark. 2004, Diskin ve ark. 2012, Diskin ve ark. 2016). Bu ölümlerin önlenmesi veya azaltılması amacıyla birçok çalışma yapılmakta ve elde edilen verilere göre çeşitli stratejiler geliştirilmektedir. Bu stratejilerden birisi de suni tohumlama sonrasi nonsteroid antiinflamatuvar ilaç uygulamasıyla annenin luteolitik cevabının azaltılmasina yöneliktir (Binelli ve ark. 2001, Dursun 2011).

Son yıllarda fertilitenin artırilmasına yönelik yapılan çalışmalarda (Güzeloğlu ve ark. 2007, Erdem ve Güzeloğlu 2010, von Krueger ve Heuwieser 2010) nonsteroid antiinflamtuvar ilaçlar ile COX enzimi inhibe edilerek, endometriyumdan $\mathrm{PGF}_{2 \alpha}$ salınımının baskılanması amaçlanmışır. Böylece korpus luteumun lize olması engellenerek korpus luteumun yaşam ömrü uzatılmaya çalışılmakta ve zayıf/yavaş gelişen embriyoların gelişimlerinin devamlılı̆̆ sağlanarak embriyonun yeterli interferon tau (IFN- $\tau$ ) salınımını gerçekleştirmesi hedeflenmektedir. Bu sayede gebe kalma oranları artırılmaya çalışılmaktadır (Young 2004). Sunulan çalışmada bu hedefe yönelik olarak; doğumdan sonra uzun süre gebe kalmamış Holstein ırk1 ineklere, tohumlama sonras1 karprofen uygulamasiyla gebe kalma oranının artırilması amaçlanmıştır.

\section{MATERYAL ve METOT}

Sunulan çalışma, Selçuk Üniversitesi Veteriner Fakültesi Deney Hayvanları Üretim ve Araştırma Merkezi Etik Kurulu'nun onayı ve izniyle yürütüldü.

Hayvan Materyali
Çalışmada en az bir kez doğum yapmış, 2-6 yaşl, seksüel siklusları düzenli olan ve genital sisteminde anatomik ve makroskobik herhangi bir sorun tespit edilmeyen, 200 Holstein $1 \mathrm{rk}$ inek kullanıldı. Çalışmaya sağımda geçen gün süresi 120 günden fazla olan inekler dahil edildi.

Belirlenen kriterler doğrultusunda seçilen ineklere rektal muayene ve ultrasonografik muayene $(6,0 \mathrm{MHz}$ linear prob, Falcovet, Pie Medical, Hollanda) yapilarak ovaryum, ovidukt, uterus ve serviks değerlendirildi (Mortimer ve ark. 1997). Genital organlarında herhangi bir sorun tespit edilmeyen, ovaryumda korpus luteum bulunan $(\mathrm{CL}+)$ ve vücut kondisyon skoru 2,75-3,75 olan inekler (Mishra ve ark. 2016) çalışmaya alındı. Buna karşıı muayeneler sırasında genital organlarında sorun belirlenen hayvanlar çalışmaya dahil edilmedi.

\section{Östrus Senkronizasyonu ve Suni Tohumlamalatın Yapılmasi}

Ovaryumda korpus luteum belirlenmiş olan ineklere, progesteron+ovsynch östrus senkronizasyon protokolü uygulandı. Bu amaçla $\mathrm{GnRH}(10 \mu \mathrm{g}$, Buserelin, Receptal ${ }^{\circledR}$, İntervet, Türkiye) kas içi enjeksiyonu ile birlikte progesteron kaynağ1 (1.38 g, CIDR 1380®, Zoetis, Türkiye) intravaginal olarak yerleştirildi (-10. gün). Yedi gün sonra progesteron kaynağ1 vaginadan çıkarıld1 ve $\mathrm{PGF}_{2 \alpha}$ (25 mg, Dinoprost, Dinolytic ${ }^{\circledR}$, Zoetis, Türkiye) kas içi enjeksiyonu yapıldı (-3. gün). PGF $_{2 \alpha}$ enjeksiyonundan 48 saat sonra $\mathrm{GnRH}$ enjeksiyonu tekrar uygulandı (-1. gün). İkinci GnRH enjeksiyonundan 12-16 saat sonra fertilitesi bilinen boğa spermalan ile sabit zamanlı tohumlamalar yapıldı (0. gün).

\section{Calışma Gruplatının Oluşturulması}

Tohumlamaları yapilan inekler rastgele 2 gruba ayrildı. -Birinci Grup (Karprofen grubu, n=100): Bu gruba dahil edilen ineklere tohumlama sonrası 14. günün sabah1 1,4 mg/kg dozda karprofen (Rimadyl XL, Zoetis, Türkiye) deri altı enjeksiyonu uygulandı.

-İkinci Grup (Kontrol grubu, n=100): Bu gruba dahil edilen ineklere tohumlama sonrası 14. günün sabahı karprofen ile aynı miktarda deri altı fizyolojik tuzlu enjeksiyonu yapıldı (Şekil 1).

\section{Gebelik Muayenelerinin Yapılması}

Gebelik muayenesi amaciyla tohumlama sonrasi 30. günde real time ultrason $(6 \mathrm{MHz}$ linear prob, Falcovet, Pie Medical, Hollanda) ile inekler muayene edildi. Uterusta non-ekojen bir bölge içerisinde hiperekojen embriyonun görülmesi gebelik pozitif olarak değerlendirildi.

\section{Istatistiksel Analiz}

Verilerin değerlendirilmesinde SPPS 25 (IBM Corp. Released 2017. IBM SPSS Statistics for Windows, Version 25.0. Armonk, NY: IBM Corp.) istatistik paket programı kullanıldı. Veri analizi yapilırken, iki grup karşılaştırması için Bağımsız 2 grup t testi (Student's t test), ön şartlar sağlanmadığında ise Mann Whitney-U 
testi, üç ve daha fazla grup karşılaştırması için Tek Yönlü Varyans Analizi ve çoklu karşılaştırma testlerinden Tukey HSD testi ile sağlanmadiğında ise Kruskal Wallis ve çoklu karşılaştırma testlerinden Bonferroni-Dunn testi kullanıldı. Testlerin anlamlılık düzeyi için $\mathrm{p}<0,05$ değeri kabul edildi.

\section{BULGULAR}

Çalışmaya dahil edilen tüm ineklerin uygulama başlangıcındaki ortalama yaşı (ay), süt verimi (kg) ve sağ1mda geçen gün süreleri (gün) sırasıyla 55,71 $\pm 21,1$; $22,56 \pm 7,75$ ve $243,53 \pm 129$, 1 olarak belirlendi (Tablo 1). Bununla birlikte çalışmada karprofen grubundan 3 ve kontrol grubundan ise 5 inek olmak üzere toplam 8 inek gebelik muayenesinden önce çeşitli nedenlerle (mastitis, ayak hastalıkları vb.) sürüden çıkarıldı̆̆ı için istatistiksel değerlendirmeye dahil edilmedi. Buna göre tohumlama sonrası 30 . günde ultrasonografi ile yapilan muayenede, gebe kalma oranlar1 karprofen grubunda $\% 42,26$, kontrol grubunda ise $\% 25,26$ olarak belirlendi $(\mathrm{p}<0,05$, Tablo 2).
İneklerin süt verimlerine göre gebe kalma oranları Tablo 3'de verildi. İnekler süt verimlerine göre $<20$, $20-30$ ve $>30 \mathrm{~kg}$ olarak 3 alt gruba ayrildı. Kontrol grubundaki ineklerin gebelik oranlarının, süt verimi arttıkça düştüğü tespit edildi. Karprofen grubunda ise süt verimi $<20 \mathrm{~kg}$ ile, $20-30 \mathrm{~kg}$ olan ineklerde gebelik oranı $>30$ kg'a göre daha yüksek belirlendi. Bununla birlikte 3 farklı süt veriminde de karprofen yapılan ineklerde gebe kalma oranı kontrol grubuna göre daha yüksek bulundu.

Doğumdan sonra uzun süre gebe kalmamış olan ineklerin sağımda geçen gün sürelerine göre gebelik oranları Tablo 4'te sunuldu. Her iki grupta da sağımda geçen gün süresinin gebe kalma oranını etkilemediği ancak karprofen uygulanan grupta gebe kalma oranlarının kontrol grubuna göre daha yüksek olduğu tespit edildi.

Tablo 1. Çalışmada kullanılan ineklerin ortalama yaşı, süt verimi ve sağımda geçen gün süreleri

Table 1. Mean age, milk yield and days in milk of cows used in the study

\begin{tabular}{cccc}
\hline Grup & Yaş (ay) & Süt Verimi (kg) & $\begin{array}{c}\text { Sağımda geçen } \\
\text { gün süresi (gün) }\end{array}$ \\
\hline Karprofen & $56,29 \pm 20,1$ & $22,28 \pm 7,88$ & $247,90 \pm 141,6$ \\
Kontrol & $55,13 \pm 22,2$ & $22,83 \pm 7,65$ & $239,06 \pm 115,5$ \\
Toplam & $55,71 \pm 21,1$ & $22,56 \pm 7,75$ & $243,53 \pm 129,1$ \\
\hline
\end{tabular}

Tablo 2. Tohumlama sonras1 30.günde yap1lan ultrasonografik muayenede elde edilen gebelik bulgular1

Table 2. Pregnancy findings obtained in the ultrasonographic examination on the 30th day after insemination

\begin{tabular}{cccccc}
\hline Grup & Gebe & $\begin{array}{c}\text { Gebe } \\
\text { değil }\end{array}$ & Toplam & $\begin{array}{c}\text { Gebelik oran } \\
(\%)\end{array}$ & P \\
\hline Karprofen & 41 & 56 & 97 & 42,26 & $<0,05$ \\
Kontrol & 24 & 71 & 95 & 25,26 & \\
\hline
\end{tabular}


Tablo 3. Süt verimlerine göre ineklerin gebelik oranlar1

Table 3. Pregnancy rates of cows according to milk yields

\begin{tabular}{ccc}
\hline Süt verimi $(\mathrm{kg})$ & Karprofen grubu & Kontrol grubu \\
\hline$\leq 20$ & $\% 47,05(16 / 34)^{\mathrm{aA}}$ & $\% 33,33(11 / 33)^{\mathrm{aA}}$ \\
$20-30$ & $\% 42,85(21 / 49)^{\mathrm{aA}}$ & $\% 25,58(11 / 43)^{\mathrm{Ab}}$ \\
$\geq 30$ & $\% 28,57(4 / 14)^{\mathrm{bA}}$ & $\% 10,52(2 / 19)^{\mathrm{bA}}$
\end{tabular}

a-b: Sütunlar içerisindeki fark; A-B: Satırlar arasındaki fark

Tablo 4. Sağımda geçen gün sürelerine göre ineklerin gebelik oranları

Table 4. Pregnancy rates of cows according to the days in milk

Sağımda geçen gün süresi

(gün) Karprofen grubu Kontrol grubu

\begin{tabular}{llc}
\hline$\leq 240$ & $\% 42,85(24 / 56)^{\mathrm{aA}}$ & $\% 25(14 / 56)^{\mathrm{Ab}}$ \\
$>240$ & $\% 41,46(17 / 41)^{\mathrm{aA}}$ & $\% 25,64(10 / 39)^{\mathrm{Ab}}$
\end{tabular}

a-b: Sütunlar içerisindeki fark; A-B: Satırlar arasındaki fark

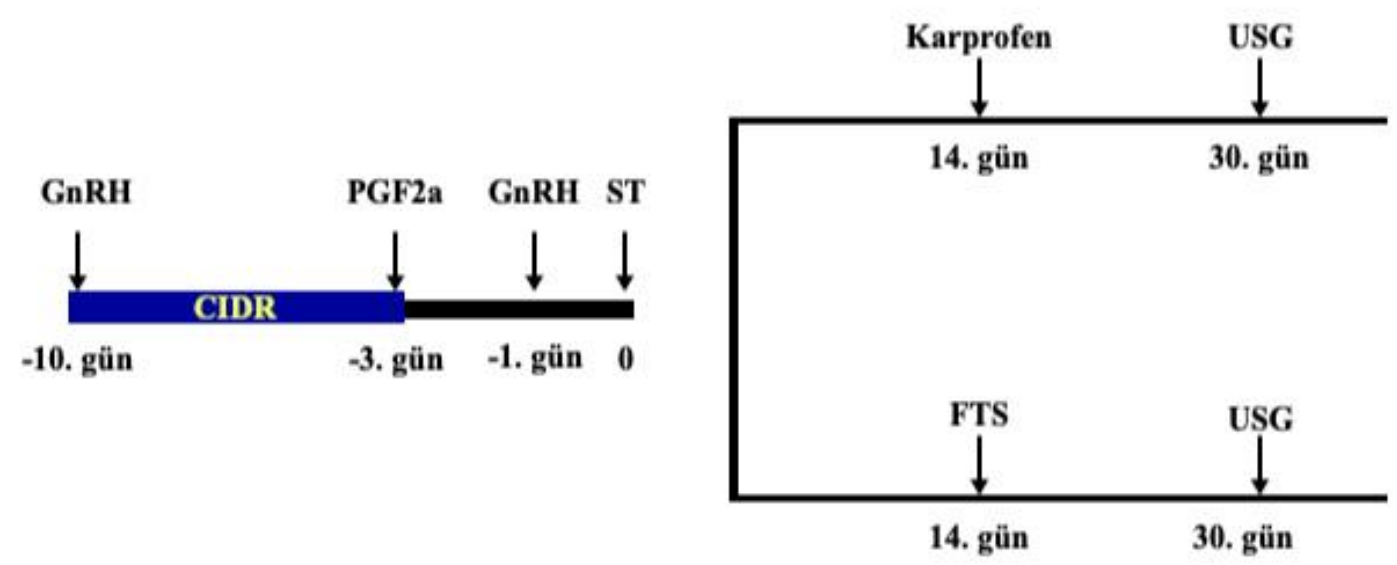

Şekil 1: Çalışmada uygulanan senkronizasyon protokolü

Figure 1: Synchronization protocol applied in the study 


\section{TARTIŞMA}

Erken embriyonik ölümlerin sütçü sığır işletmelerinde en önemli sorunlardan biri olduğu bildirilmektedir (Diskin ve ark. 2012, Diskin ve ark. 2016). Yapılan çalışmalarda düvelerde ve orta verimli ineklerde fertilizasyon oran1 \%90-100 iken, yüksek verimli ineklerde bu oranın \%85-95 arasında değiştiği bildirilmektedir. Fertilizasyon oranı bu derece yüksek olmasına rağmen buzağılama oranı \%55 düzeyinde gerçekleşmektedir. Fertilizasyon-doğum arasındaki kayıpların yaklaşık \%40'1nın erken/geç embriyonik ölümlerden kaynaklandığ1 düşünülmektedir (Thatcher ve ark. 1994, Walsh ve ark. 2011, Diskin ve ark. 2016). Bu kayıpların da büyük bir kısmının gebeliğin maternal kabulünden önce şekillendiği bildirilmektedir (Santos ve ark. 2004, Morris ve Diskin 2008, Wiltbank ve ark. 2016).

Erken gebelik döneminde maternal kabulün gerçekleşebilmesi için embriyo ve anne arasında önemli bir etkileşim söz konusudur. Bu süre zarfında anne ve embriyo arasinda senkronizasyon farklılıkları meydana geldiğinde embriyonik kayılar şekillenmektedir. Diğer bir ifadeyle embriyonun gelişim dönemi ve annenin siklusu (maternal ortam) arasinda 12-24 saatten fazla bir fark oluştuğunda embriyonik ölümler gelişebilmektedir (Lonergan ve Forde 2014). Çünkü maternal ortam ile embriyo arasindaki asenkroni embriyonun gelişimini zayıflatmaktadır. Zayıf gelişen embriyolar az veya belirlenemeyecek miktarlarda IFN$\tau$ üretmekte ve sonuçta maternal kabul döneminde $\mathrm{PGF}_{2 \alpha}$ salınımını engelleyememektedir. Çünkü IFN$\tau$ 'nun temel olarak görevi endometriyumdan pulzatil $\mathrm{PGF}_{2 \alpha}$ salinimini durdurarak korpus luteumun regresyonunu engellemektir. IFN- $\tau$, bu etkisini endometriyumdaki östrojen reseptör- $\alpha$ ve oksitosin reseptörlerini baskılayarak gerçekleştirmektedir (Vural ve ark 2012). Bu nedenle zayıf gelişen embriyoların yeterince IFN- $\tau$ salg1layamaması nedeniyle embriyonik ölümler kaçınılmaz olmaktadır (Mann ve Lamming 1999, Thatcher ve ark. 1997, Thatcher ve ark. 2006, Erdem ve Güzeloglu 2010, Alkan ve Erdem 2018). Bu kayıpları azaltmak ve fertilitenin artırılması amaciyla son y1llarda tohumlamadan sonra farklı günlerde nonsteroid antiinflamatuvar ilaçların uygulanabileceği bildirilmektedir (Binelli ve ark. 2001, Thatcher ve ark. 1997, Güzeloğlu ve ark. 2007, Erdem ve Güzeloğlu 2010, Dursun 2011, Alkan ve Erdem 2018). Sunulan çalışmada da COX-2 inhibitörü olan karprofen uygulamasiyla, maternal kabul döneminde $\mathrm{PGF}_{2 \alpha}$ salınımı baskılanarak korpus luteumun ömrünün uzatılması ve zayıf gelişen embriyoya yeterli IFN- $\tau$ üretmesi için zaman kazandırılması amaçlanmıştır. Bu amaçla tohumlama sonrası 14. günde karprofen uygulamasinın, gebe kalma oranını kontrol grubuna göre $\% 17$ artırdığ1 tespit edilmiştir. Gebe kalma oranında elde edilen bu olumlu etkiye bağlı olarak tohumlama sonrası 14. günde karprofen uygulamasinın fertilitenin arttırılmasına yönelik yeni bir strateji olarak değerlendirilebileceği düşünülmüştür. Ayrıca karprofenin sütte kalıntı birakmaması, bilinen yan etkisinin olmaması ve tek enjeksiyonun yeterli olmas1 diğer nonsteroid antiinflamatuvar ilaçlara göre avantaj sağlamaktadır (CVMP 2004, von Krueger ve Heuwieser 2010).

Fertilitenin artırilmasi amaciyla suni tohumlama sonrası nonsteroid antiinflamatuvar ilaçların uygulandığ1 birçok çalışmada gebe kalma oranlarında farklı sonuçlar elde edilmiştir (Güzeloğlu ve ark. 2007, Erdem ve Güzeloğlu 2010, von Krueger ve Heuwieser 2010, Emre ve ark. 2012). Bu farklilıkların oluşmasinda hayvan materyali (inek, düve), kullanılan nonstereroid antiinflamatuvar ilaç (fluniksin meglumin, karprofen, meloksikam), uygulama yolu, günü ve süresi gibi birçok faktör etkili olmaktadır (Alkan ve Erdem 2018).

Güzeloğlu ve ark. (2007), Holstein düvelerde yaptıkları çalışmada suni tohumlama sonrası 15 ve 16 . günlerde fluniksin meglumin uygulamasinin gebe kalma oranını artırdığını bildirmişlerdir. Gebe kalma oranlarındaki artışın; uygulanan fluniksin megluminin, luteolizisi geciktirerek muhtemelen zayıf olarak gelişen embriyoların hayatta kalma şansinı artırmasından kaynaklandığını ifade etmektedirler. Nitekim yapılan bir çalışmada (Odensvik ve ark. 1998) östrus siklusunda oral olarak uygulanan fluniksin megluminin uterusta $\mathrm{PGF}_{2 \alpha}$ sentezini ve salınımını engellediği tespit edilmiştir. Bu sayede korpus luteumun ömrünün ve siklusun 5-6 gün uzadiğ1, progesteron seviyesinin fluniksin uygulamasından etkilenmediği ve luteal fazın uzamasına bağlı olarak progesteron miktarının arttı̆̆ tespit edilmiştir. Amiridis ve ark. (2009) ise Holstein düvelere östrus siklusunun 16, 17 ve 18. günlerinde uygulanan meloksikamın östrus siklusunun süresini kontrol grubuna göre uzattı̆̆ını belirlemişlerdir. Bu uzamanın nedeninin prostaglandin salınımının inhibe edilmesinden veya zayıf gelişen embriyonun yaşam süresinin uzatılmasından kaynaklandığı bildirilmiştir (Amiridis ve ark. 2009).

Emre ve ark. (2012), sütçü ineklerde suni tohumlama sonras1 13 ve 14 . günlerde 12 saat arayla uygulanan fluniksin meglumin kontrol grubuna göre gebe kalma oranlarını artırdığını ancak bu farklılığın istatistiksel olarak anlamlı olmadığını bildirmişlerdir. Repeat breeder düvelerde yapılan bir çalışmada ise tohumlama sonrası 15-16. günlerde uygulanan fluniksin megluminin gebe kalma oranını (fluniksin meglumin grubu $\% 50$ ve kontrol grubu $\% 20, p>0,05)$ artirmada etkili olabileceği belirlenmiştir (Doğruer ve ark. 2007). Amiridis ve ark. (2009) da repeat breeder ineklerde suni tohumlama sonrası 16 ve 18 . günlerde meloksikam uygulamasının gebe kalma oranını artırdığı bildirmişlerdir.

Suni tohumlama sonrasi uygulanan nonsteroid antiinflamatuvar ilaçların gebe kalma oranını artırdığını bildiren çalışmalar olduğu gibi herhangi bir etkisinin olmadığını veya olumsuz etki oluşturduğunu bildiren araştırmalar da mevcuttur (Dursun 2011, Lucacin ve ark. 2018, von Krueger ve Heuwieser 2010). Dursun 
(2011) suni tohumlama sonrasi uygulanan fluniksin meglumin ve ketoprofenin; von Krueger ve Heuwieser (2010) fluniksin meglumin ve karprofenin; Lucacin ve ark. (2018) ise fluniksin megluminin gebe kalma oranı üzerine herhangi bir etkisinin olmadığını bildirmişlerdir.

Erdem ve Güzeloğlu (2010), Holstein 1rk1 düvelere suni tohumlama sonrasi 15 . günde yapilan meloksikamın gebe kalma oranını (meloksikam grubu $\% 24,3$, kontrol grubu $\% 52, \mathrm{p}<0,05)$ düşürdüğünü bildirmişlerdir. $\mathrm{Bu}$ sonuçlar doğrultusunda meloksikamın sığırlarda gebelik esnasında kullanılmasının güvenli olduğu düşünülmesine rağmen gebeliğin maternal kabulü sürecinde zararlı olabileceği vurgulanmıştır. $\mathrm{Bu}$ zararlı etkinin nedeninin, meloksikamın yarılanma ömrünün oldukça uzun olmasindan dolayı prostaglandin aktivitesini olumsuz etkilemesinden kaynaklandığı düşünülmektedir. Çünkü prostaglandinlerin periimplantasyon aşamasında da görev aldığı bilinmektedir. Uzun etkili bir nonsteroid antiinflamatuvar ilacin maternal kabul ve implantasyon sürecinde kullanılmasının gebe kalma oranını düşürebileceği vurgulanmıştır (Weems ve ark. 2006, Erdem ve Güzeloğlu 2010, Spencer ve ark. 2013). Bununla birlikte fertilitenin arttırlması amaciyla tohumlama sonrasi yapılacak bütün destek uygulamalarında uterusta sağlıklı bir embriyonun bulunması gerekmektedir. Çünkü sığırlarda farklı nedenlere bağlı olarak çok erken dönemde de (0-7. günler) embriyonik ölümler meydana gelebilmektedir (Inskeep ve Dailey 2005). Bu sorunun ortaya çıkmasında oosit kalitesi ve folikül gelişimi oldukça önemli bir yere sahiptir (Morris ve Diskin 2008). Çünkü oosit kalitesi başarılı bir fertilizasyon sonrası, blastosist gelişim dönemi ve maternal kabul dönemi üzerine direkt etkiye sahiptir (Watson 2007). Sunulan çalışmada da olduğu gibi tohumlama sonrası karprofen uygulamasının başarısı, uterusta embriyo varlığında etkili olabilecek bir yöntemdir. Dolasıyla doğumdan sonra uzun süre gebe kalmayan ineklerde gebelik oranında elde edilen \%17 artış, bu hayvanlarda destek sağlanabilecek bir embriyo varlığına işaret etmektedir. İneklerde fertilite ve süt verimi arasında yakın bir ilişki olduğu ve yüksek süt verimli ineklerde döl veriminin azaldığ1 bildirilmektedir (Nebel ve McGillard 1993, LeBlanc 2013, Bedere ve ark. 2018). Çünkü süt verimi arttıkça karaciğer klirensi yükselmekte ve steroid metabolizması hızlanmaktadır. Bunun sonucu olarak steroid hormon (progesteron ve östrojen) seviyeleri düşmektedir. Sonuç olarak da gebelik oranı gibi birçok reprodüktif parametre olumsuz etkilenmektedir (Wathes ve Taylor 2002, Walsh ve ark. 2011, LeBlanc 2013, Berry ve ark. 2016). Alkan ve Erdem (2020) ve Mellado ve ark. (2012) repeat breeder sütçü ineklerde, Buckley ve ark. (2003), Gabor ve ark. (2008) ve Hagiya ve ark. (2013) sütçü ineklerde, süt verimi arttıkça gebe kalma oranının düştügünü tespit etmişlerdir. Vasconcelos ve ark. (2006) ise yüksek süt verimli ineklerde gebelik oranının daha düşük olduğunu ve embriyonik ölüm oranının daha yüksek olduğunu bildirmişlerdir. Yapılan bir meta analiz çalışmasında ise süt veriminin fertilite ile yakından ilişkili olduğu ve süt miktarının artmasının embriyonik kayıplara neden olduğu tespit edilmiştir (Bedere ve ark. 2018). Sunulan çalışmada da kontrol grubunda süt verimi yüksek olan ineklerde $(\geq 30 \mathrm{~kg})$ gebelik oranı diğer ineklere göre daha düşük bulunmuştur. Ancak süt verimi yüksek olan ineklere karprofen uygulamasinin kontrol grubuna göre gebe kalma oranını artırabileceği tespit edilmiştir. $\mathrm{Bu}$ artışın nedenin yüksek süt verimli ineklerde embriyonik ölümlerin azaltılmasından kaynaklanabileceği düşünülmüştür. Çünkü yüksek süt verimli ineklerde progesteron yetersizliğine bağlı olarak embriyonun gelişimi sekteye uğramaktadır. Bunun sonucunda ise embriyo luteolizisi engellemek için yeterli miktarda IFN- $\tau$ salgilayamamakta ve embriyonik ölümler kaçınılmaz olmaktadır (Mann ve Lamming 1999, Walsh ve ark. 2011, Diskin ve ark. 2016). Ancak yapilan karprofen uygulamasinin luteolizisi engelleyerek yavaş gelişen ve yeterli IFN- $\tau$ salgilayamayan embriyoya zaman kazandırarak gelişimine devam etmesini sağladığı düşünülmektedir. Bu sayede doğumdan sonra uzun süre gebe kalmamış ve yüksek süt verimli ineklerde karprofen uygulamasının gebe kalma oranını artırmada etkili olabileceği kanısına varılmıştır.

Sütçü sığır işletmelerinde, ineklerin doğumdan sonra gebe kalmadan geçirdikleri süre (açık gün) karlı bir yönetim için oldukça önemli bir kriterdir (De Vries 2006). İşletmeden işletmeye farkl1lık göstermekle birlikte ineklerin istenilen sinırlar içerisinde (postpartum $<120$ gün) gebe kalamamas1 ciddi ekonomik kayıplara neden olmaktadır. Bu nedenle ineklerin doğumdan kısa bir süre sonra yeniden gebe kalması istenilmektedir (Ferguson ve Skidmore 2013). Ancak sunulan bu çalıșmada materyal olarak kullanılan ineklerin gebe kalmadan geçirdikleri süre (ortalama

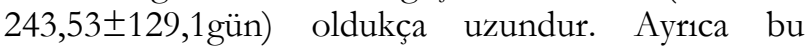
çalışmada ineklerin gebelik oranları ortalama sağımda geçen gün sürelerine ( $\leq 240$ ve $>240$ gün) göre de değerlendirilmiştir. Her iki grupta da sağımda geçen gün süresinin gebe kalma oranını etkilemediği tespit edilmiştir. Özellikle sağımda geçen gün süresinin uzamasina neden olan repeat breeder ineklerde yapilan çalışmalarda da sağımda geçen gün süresinin gebelik oranını etkilemediği tespit edilmiştir (Villarroel ve ark. 2004, Shams-Esfandabadi ve Shirazi 2006, ShamsEsfandabadi ve ark. 2007, Alkan ve Erdem 2020). Bununla birlikte Fischer-Tenhagen ve ark. (2010) ve Mellado ve ark. (2012) ise gebe kalma oranının, ineklerin sağımda geçen gün süreleri arttığında düştüğünü bildirmişlerdir.

\section{SONUÇ}

Sonuç olarak doğumdan sonra uzun süre gebe kalmamıs olan ineklere, tohumlama sonrası 14. günde 
karprofen uygulamasının gebe kalma oranını artırmada etkili olabileceği kanısına varıldı. Bununla birlikte süt veriminin gebelik oranını etkilediği ve yüksek süt verimli ineklere karprofen uygulamasının gebe kalma oranını artırabileceği tespit edildi. Ancak sağımda geçen gün süresinin gebe kalma oranını etkilemedi belirlendi.

Proje Destek Bilgileri: Bu çalışma, Selçuk Üniversitesi Bilimsel Araştırma Projeleri Koordinatörlüğü tarafindan 19401008 proje numarası ile desteklenmiştir.

Etik Kurul Bilgileri: Bu çalışma Selçuk Üniversitesi Veteriner Fakültesi Deney Hayvanları Üretim ve Araştırma Merkezi Etik Kurulu'nun onay1 (2018/181) ve izniyle yürütüldü.

Teşekkür: $\mathrm{Bu}$ çalışmada istatistiksel analizlerin yapilmasına yardımcı olan Doç. Dr. M. Agah TEKINNDAL'a teşekkür ederiz.

Çıkar Çatışması: Yazarlar, çıkar çatışması olmadığını beyan eder.

\section{KAYNAKLAR}

Alkan H, Erdem H. Repeat breeder ineklerde tohumlama sonras yapılan hormonal desteğe, laktasyon sayısı, süt verimi ve sağımda geçen gün süresinin etkisi. Eurasian J Vet Sci. 2020; 36(4): 298-305.

Alkan H, Erdem H. Ineklerde nonsteroid antiinflamatuar ilaçların reprodüktif amaçlı kullanımı. Ataturk Univ Vet Bil Derg. 2018; 13(1): 112-120.

Amiridis GS, Tsiligianni T, Dovolou E, Rekkas C, Vouzaras D, Menegatos I. Combined administration of gonadotropin-releasing hormone, progesterone, and meloxicam is an effective treatment for the repeat-breeder cow. Theriogenology. 2009; 72(4): 542-548.

Bartlett PC, Kirk JH, Mather EC. Repeated insemination in Michigan Holstein-Friesian cattle: incidence, descriptive epidemiology and estimated economic impact. Theriogenelogy. 1986; 26(3): 309-322.

Bedere N, Cutullic E, Delaby L, Garcia-Launay F, Disenhaus C. Meta-analysis of the relationships between reproduction, milk yield and body condition score in dairy cows. Livest Sci. 2018; 210: 73-84.

Berry DP, Friggens NC, Lucy M, Roche JR. Milk production and fertility in cattle. Annu Rev Anim Biosci. 2016; 4: 269-290.

Binelli M, Thatcher WW, Mattos R, Baruselli PS. Antiluteolytic strategies to improve fertility in cattle. Theriogenology, 2001; 56(9): 1451-1463.

Buckley F, O'sullivan K, Mee JF, Evans RD, Dillon P. Relationships among milk yield, body condition, cow weight, and reproduction in spring-calved HolsteinFriesians. J Dairy Sci. 2003; 86(7): 2308-2319.
CVMP. Committee for veterinary medicinal products: Carprofen (Extension to dairy cattle) summary report (3). EMEA/MRL/914/04-FINAL. Retrieved from: https://www.ema.europa.eu/en/documents/mrlreport/carprofen-summary-report-3-committeeveterinary-medicinal-products_en.pdf Accessed date: 29.12.2020.

De Vries A. Determinants of the cost of days open in dairy cattle. In proceedings of the 11 th international symposium on veterinary epidemiology and economics. 2006; pp. 19-20.

Diskin MG, Parr MH, Morris DG. Embryo death in cattle: an update. Reprod Fertil Dev. 2012; 24(1): 244-251.

Diskin MG, Waters SM, Parr MH, Kenny DA. Pregnancy losses in cattle: potential for improvement. Reprod Fertil Dev. 2016; 28(2): 83-93.

Dochi O, Takahashi K, Hirai T, Hayakawa H, Tanisawa M, Yamamoto Y, Koyama H. The use of embryo transfer to produce pregnancies in repeat-breeding dairy cattle. Theriogenology. 2008; 69 (1):124-128.

Doğruer G, Sarıbay MK, Karaca F. Repeat breeder sorunlu düvelerde fluniksin meglumin uygulamalarının gebelik oranı üzerine etkisi. Fırat Univ Saglık Bilim Derg. 2007; 21(6): 263-268.

Dursun Ş. Laktasyonda olmayan İsviçre Esmeri İnek ve düvelerde ketoprofen ve flunixin meglumin uygulamasının gebe kalma oranı üzerine etki. Doktora Tezi, Selçuk Üniversitesi Sağlık Bilimleri Enstitüsü, Konya, 2011.

Emre B, Zonturlu AK, Korkmaz Ö. Sütçü ineklerde ovsynch protokolünü takiben uygulanan fluniksin meglumin'in gebelik oranı üzerine etkisi. Harran Üniv Vet Fak Derg. 2012; 1(2): 88-91.

Erdem H, Güzeloğlu A. Effect of meloxicam treatment during early pregnancy in holstein heifers. Reprod Dom Anim. 2010; 45: 625-628.

Ferguson JD, Skidmore A. Reproductive performance in a select sample of dairy herds. J Dairy Sci. 2013; 96(2): 1269-1289.

Fischer-Tenhagen C, Thiele G, Heuwieser W, Tenhagen BA. Efficacy of a treatment with hCG 4 days after AI to reduce pregnancy losses in lactating dairy cows after synchronized ovulation. Reprod Domest Anim. 2010; 45(3): 468-472.

Gabor G, Tóth F., Ózsvári L, Abonyi-Tóth Z, Sasser RG. Factors influencing pregnancy rate and late embryonic loss in dairy cattle. Reprod Domest Anim. 2008; 43(1): 53-58.

Güzeloğlu A, Erdem H, Saribay MK, Thatcher WW, Tekeli T. Effect of the administration of flunixin meglumine on pregnancy rates in Holstein heifers. Vet Rec. 2007; 160: 404-406.

Hagiya K, Terawaki Y, Yamazaki T, Nagamine Y, Itoh F, Yamaguchi S, Abe H, Gotoh Y, Kawahara T, Masuda Y, Suzuki M. Relationships between conception rate in Holstein heifers and cows and milk yield at various stages of lactation. Animal. 2013; 7(9): 1423. 
Inskeep EK, Dailey RA. Embryonic death in cattle. Vet Clin Food Anim Prac. 2005; 21(2): 437-461.

LeBlanc SJ. Is a high level of milk production compatible with good reproductive performance in dairy cows?. Anim Front. 2013; 3(4): 84-91.

Lonergan P, Forde N. Maternal-embryo interaction leading up to the initiation of implantation of pregnancy in cattle. Animal. 2014; 8(s1): 64-69.

Lucacin E, Pinto-Neto A, Mota M, Acco A, Souza M, Alberton J, Silva A. Effects of flunixin meglumine on reproductive parameters in beef cattle. Anim Reprod. 2018; 7(2): 75-79.

Mann GE, Lamming GE. The influence of progesterone during early pregnancy in cattle. Reprod Dom. 1999; 34: 269-274.

Mellado M, Zuñiga A, Veliz FG, de Santiago A, Garcia JE, Mellado J. Factors influencing pregnancy per artificial insemination in repeat-breeder cows induced to ovulate with a CIDR-based protocol. Anim Reprod Sci. 2012; 134(3-4): 105-111.

Mishra S, Kumari K, Dubey A. Body condition scoring of dairy cattle: A review. RRJVS, 2016; 2, 58-65.

Morris D, Diskin M. Effect of progesterone on embryo survival. Animal. 2008; 2(8):1112-1119.

Mortimer RG, Farin PW, Stevens RD. Reproductive examination of the non- pregnant cow. In: Current Therapy in Large Animal Theriogenology. Ed; Youngquist RS, W.B Saunders Co., Philadelphia, USA. 1997; pp.268275.

Nebel RL, McGilliard ML. Interactions of high milk yield and reproductive performance in dairy cows. J Dairy Sci. 1993; 76(10): 3257-3268.

Odensvik K, Gustafsson H, Kindahl H. The effect on luteolysis by intensive oral administration of flunixin granules in heifers. Anim Reprod Sci. 1998; 50(1-2): 35-44.

Perez-Marin CC, Moreno LM, Calero GV. Clinical approach to the repeat breeder cow syndrome. In: A bird's-eye view of veterinary medicine, Ed; Perez-Marin CC, 1st Ed, Intech, Rijeka, Croatia. 2012; pp. 337-362.

Santos JEP, Thatcher WW, Chebel RC, Cerri RLA, Galvao $\mathbf{K N}$. The effect of embryonic death rates in cattle on the efficacy of estrus synchronization programs. Anim Reprod Sci. 2004; 82: 513-535.

Shams-Esfanabadi N, Shirazi A. Effects of supplementation of repeat-breeder dairy cows with CIDR from 5-19 postinsemination on pregnancy rate. Pakistan J Biol Sci, 2006; 9(11): 2173-2176.

Shams-Esfandabadi N, Shirazi A, Mirshokrai P, Bonyadian M. Influence of hCG administration after AI on conception rates and serum progesterone concentration in cattle. PJBS, 2007; 10(16): 2709.

Spencer TE, Forde N, Dorniak P, Hansen TR, Romero JJ, Lonergan P. Conceptus-derived prostaglandins regulate gene expression in the endometrium prior to pregnancy recognition in ruminants. Reproduction. 2013; 146(4): 377-387.

Thatcher WW, Binelli M, Burke J, Staples CR, Ambrose JD, Coelho S. Antiluteolytic signals between the conceptus and endometrium. Theriogenology, 1997; 47(1): 131-140.

Thatcher WW, Guzeloglu A, Bilby TR. Early embryonic mortality in modern dairy cows: causes, consequences and remedies. Vlaams Diergen Tijds. 2006; 75: 106-113.

Thatcher WW, Staples CR, Danet-Desnoyers G, Oldick B, Schmitt EP. Embryo health and mortality in sheep and cattle. J Anim Sci Technol. 1994; 72: 16-30.

Vasconcelos JLM, Demétrio DGB, Santos RM, Chiari JR, Rodrigues CA, Sa Filho OG. Factors potentially affecting fertility of lactating dairy cow recipients. Theriogenology, 2006; 65(1): 192-200.

Villarroel A, Martino A, BonDurant RH, Dèletang F, Sischo WM. Effect of post-insemination supplementation with PRID on pregnancy in repeat-breeder Holstein cows. Theriogenology, 2004; 61(7-8): 1513-1520.

von Krueger X, Heuwieser W. Effect of flunixin meglumine and carprofen on pregnancy rates in dairy cattle. J Dairy Sci. 2010; 93: 5140-5146.

Vural MR, Güzeloğlu A, Küplülü ş. Gebelik fizyolojisi. In: Çiftlik Hayvanlarında Doğum ve Jinekoloji. Eds: Semacan A, Kaymaz M, Findık M, Rişvanlı A, Köker A, 1st ed, Medipres, Malatya, Türkiye. 2012; pp. 125-156.

Walsh SW, Williams EJ, Evans ACO. A review of the causes of poor fertility in high milk producing dairy cows. Anim Reprod Sci. 2011; 123(3-4): 127-138.

Wathes C, Taylor V. Fertility in High Yielding Dairy Cows. Holstein J. 2002; 1: 108-118.

Watson AJ. Oocyte cytoplasmic maturation: a key mediator of oocyte and embryo developmental competence. J Anim Sci. 2007; 85(suppl_13): E1-E3.

Weems CW, Weems YS, Randel RD. Prostaglandins and reproduction in female farm animals. Vet J, 2006; 171(2): 206-228.

Wiltbank MC, Baez GM, Garcia-Guerra A, Toledo MZ, Monteiro PL, Melo LF, Ochoa JC, Santos JEP, Sartori R. Pivotal periods for pregnancy loss during the first trimester of gestation in lactating dairy cows. Theriogenology. 2016; 86(1): 239-253.

Young CD. Reproductive efficiency following administration of an inhibitor of prostaglandin F2 $\alpha$ during early embryonic development in dairy cattle. Master thesis, The University of Tennessee, Knoxville, 2004. 